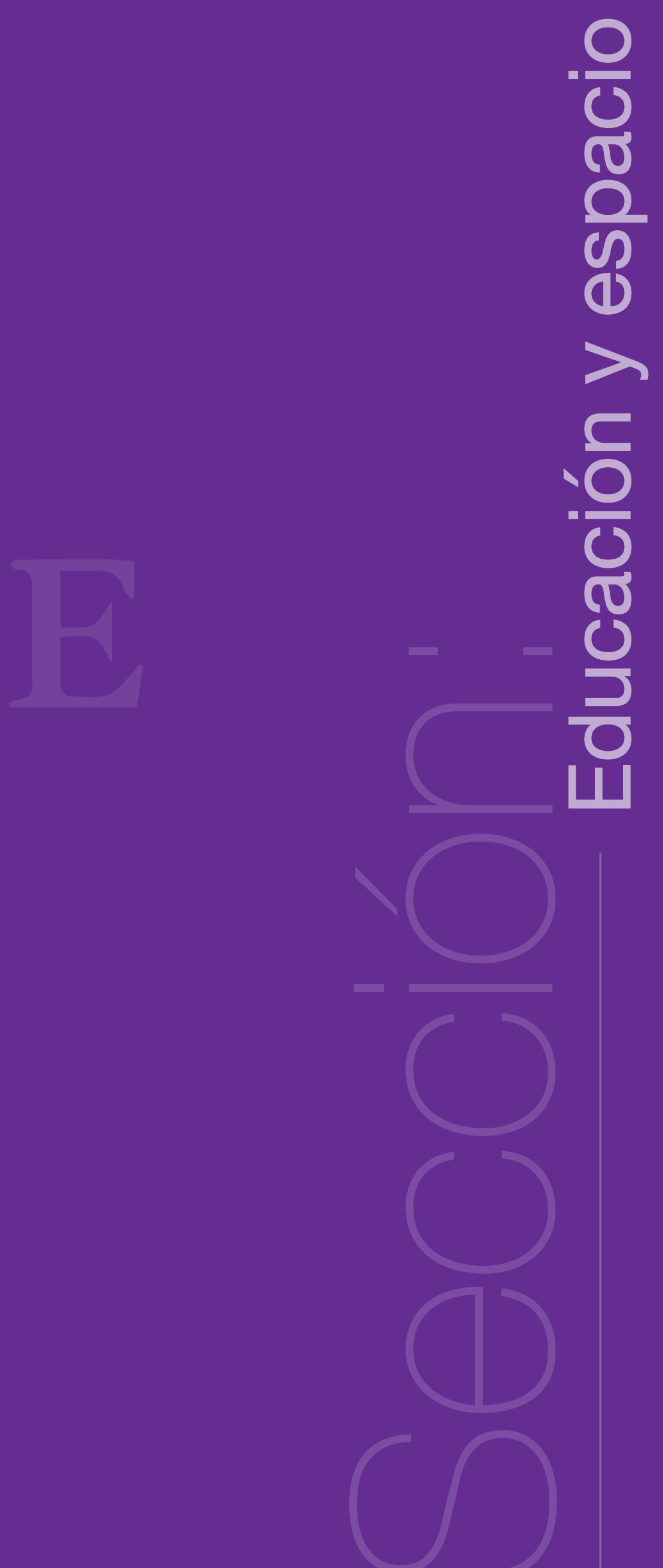



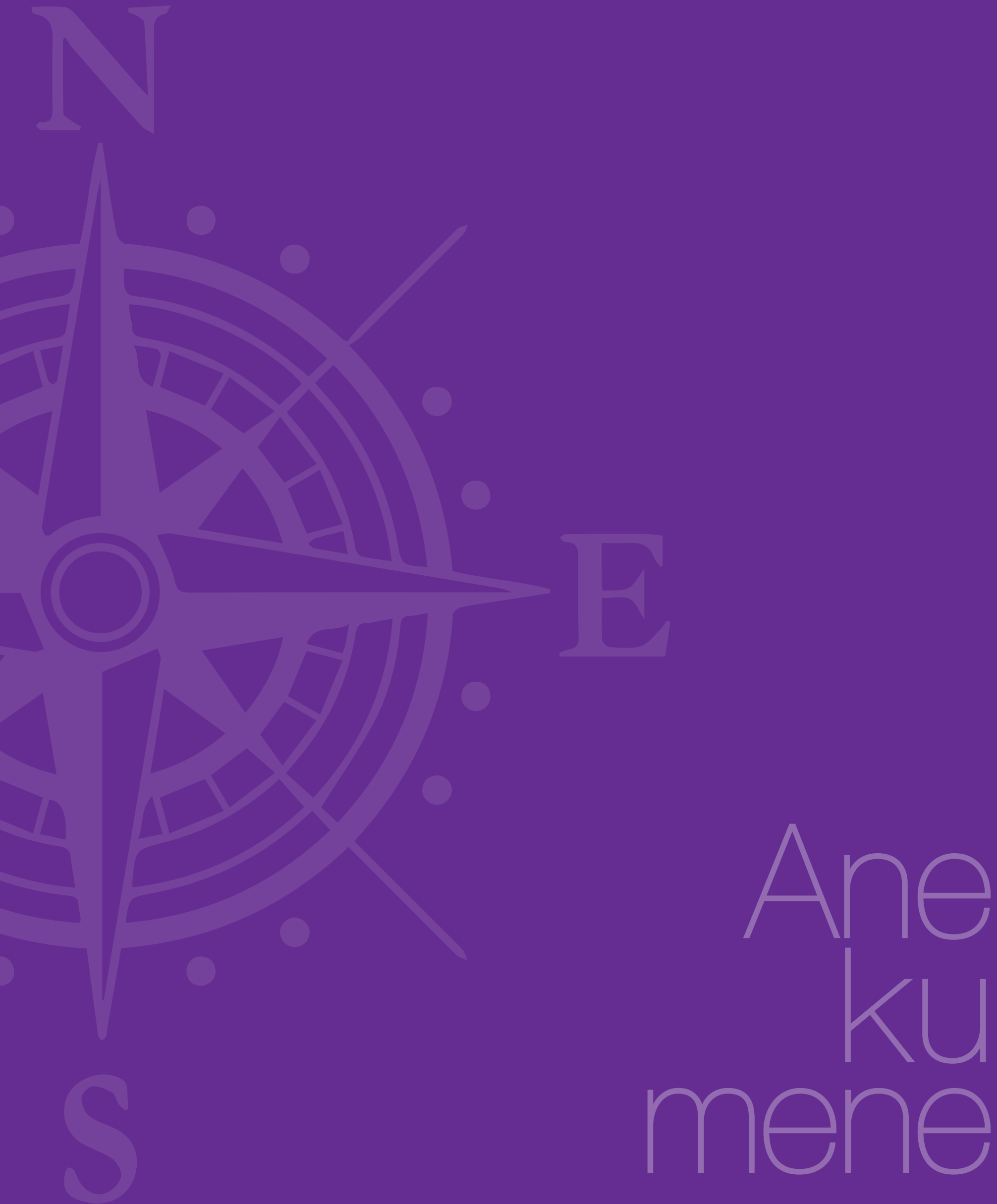


\section{História e Geografia na Educação Básica (6-I2 anos) e a (in)visibilidade dos lugares da cidade}

\section{Historia y Geografía en la Educación Básica (6-I2 años) y la (in)visibilidad de los lugares de la ciudad}

History and Geography in Primary School (6-I2 years old) and the city places' (in)visibility

Alfredo Gomes Dias

Maria João Hortas ${ }^{1}$

\section{Resumo}

O carácter sistémico e integrado do conhecimento histórico-geográfico implica identificar as potencialidades das áreas disciplinares de Estudo do Meio Social e de História e Geografia de Portugal (6-12 anos), no sentido da construção e implementação de currículos locais. Esta abordagem ao ensino e aprendizagem das Ciências Sociais naquelas idades pressupõe (1) estabelecer a relação entre as potencialidades do património local, material e imaterial, e a construção de um currículo local; (2) desenvolver métodos e técnicas específicas da História e da Geografia para a análise dos recursos patrimoniais dos lugares; (3) valorizar o património local e a sua pertinência na articulação com o Currículo Nacional.

\section{Palavras-chave}

Património local;

flexibilidade curricular;

lugar; competências

1 Universidad de Lisboa 


\section{Palabras clave}

patrimonio local;

flexibilidad curricular;

lugar; competencias

\title{
Resumen
}

La naturaleza sistémica e integrada del conocimiento histórico y geográfico permite, desde las posibilidades que ofrecen las áreas de Estudio del Entorno Social y de Historia y Geografía de Portugal (6-12 años), implementar los currículos locales centrados en elementos patrimoniales reconocidos (visibles) o ignorados (invisibles) por la comunidad. Hay también un segundo nivel de invisibilidad de los lugares, que se produce tras el conocimiento que tenemos de ellos, cuando se les dan nuevos significados. Trabajar esta invisibilidad de los lugares incluye la identificación, el conocimiento y el análisis del patrimonio que le da singularidad. Esto solo es posible si lo integramos como recurso para la enseñanza y el aprendizaje del entorno local, permitiendo la construcción de puentes hacia el currículo nacional. Así, la enseñanza de las Ciencias Sociales presupone: (1) establecer una relación entre el potencial del patrimonio local, material e inmaterial para construir un currículo local; (2) el desarrollo de métodos y técnicas específicas de la historia y la geografía para el análisis de los lugares; (3) la valorización del patrimonio local y su importancia en relación con el currículo nacional.

\section{Abstract}

\author{
Keywords \\ local heritage; \\ curricular flexibility; \\ place; skills
}

The systemic and integrated nature of historical and geographical knowledge involves identifying the potentialities of the subjects Study of Social Environment and History and Geography of Portugal (6-12 years), in order to implement local curricula. This approach to the teaching and learning of Social Sciences in these ages requires (1) the establishment of the relationship between the potentialities of the local heritage, both tangible and intangible, and the construction of a local curriculum; (2) the development of specific methods and techniques of history and geography for the analysis of heritage resources of the places; (3) the enhancement of the local heritage and its relevance in conjunction with the national curriculum. 


\section{Introdução}

O meio - natural, social e cultural- disponibiliza importantes recursos que, uma vez mobilizados na sala de aula, contribuem de forma relevante para o desenvolvimento de alunos histórica e geograficamente competentes.

No caso concreto de Lisboa, os lugares da cidade apresentam um sem número de elementos patrimoniais que se mantêm, muitas vezes, ocultos ao cidadão comum. Essa invisibilidade é provocada quer pelo ritmo em que vive uma população que habita uma grande cidade, quer pelo desconhecimento que deles se tem, em particular, dos seus significados mais profundos.

Deste modo, no âmbito da formação inicial de professores que se realiza na Escola Superior de Educação de Lisboa (ESELX), mantém-se a aposta numa componente formativa que tenta proporcionar, aos futuros professores, o contacto com uma metodologia de ensino que concilia diferentes vertentes complementares: a mobilização do património local, tendo em vista dar significado às aprendizagens prescritas no currículo nacional; a opção pela aprendizagem por projeto, enquanto metodologia promotora de atividades investigativas e participativas; a escolha de um processo de ensino e aprendizagem centrado no desenvolvimento de competências, contribuindo para a formação de cidadãos civicamente interventivos.

Neste estudo propomo-nos analisar os projetos didáticos concebidos pelos estudantes de Mestrado em Educação do $1^{\circ}$ e $2^{\circ}$ Ciclo do Ensino Básico (6-12 anos), durante a frequência da Unidade Curricular Temas da História e Geografia de Portugal (THGP). Nesses projetos são definidos lugares da cidade de Lisboa; identificados elementos do património natural, social e cultural; definidos objetivos de aprendizagem; concebidas estratégias e atividades a implementar; e estabelecidas competências histórico-geográficas a desenvolver.

A concretização desta análise realiza-se em três momentos fundamentais: (1) o enquadramento teórico sobre as relações entre o património local e o currículo nacional, entre a flexibilidade curricular e a metodologia de projeto, e entre os elementos do património local e a (in)visibilidade dos lugares; (2) a apresentação da experiência formativa na ESELX em torno da conceção de projetos pedagógicos assentes nas características singulares dos diferentes lugares da cidade; e (3) a análise da relação entre território da cidade, (in)visibilidade dos lugares e desenvolvimento de competências da História e da Geografia.

\section{Património local, currículo local e invisibilidade dos lugares}

Uma das finalidades da unidade curricular THGP é a de proporcionar aos estudantes o contacto e experimentação de um conjunto de ferramentas/ estratégias facilitadoras de uma abordagem ao estudo do meio social numa lógica local. Assim, pretende-se que o trabalho desenvolvido se oriente para o desenvolvimento de competências que permitam, aos futuros professores, saber mobilizar os recursos do meio local e gerir o currículo nacional numa lógica de currículo local, assegurando aos destinatários aprendizagens ativas, significativas e socializadoras.

O programa de História e Geografia de Portugal (10-12 anos) define, como um dos contributos da disciplina, que os alunos "desenvolvam atitudes que favoreçam o seu conhecimento do presente e do passado, despertando-lhes o interesse pela intervenção no meio em que vivem, pela atividade humana nesse meio, pelos traços visíveis dessa atividade" ${ }^{2}$ devendo os alunos, no seu perfil de saída, saber "interessar-se pela preservação do património natural e cultural" e "reconhecer testemunhos do património natural e cultural, regional e nacional" ${ }^{3}$. Nas diversas estratégias de abordagem sugeridas é aberto o caminho para a mobilização e vivência do meio local, o que nos remete para as questões de proximidade. Por sua vez, a estrutura organizativa e as propostas de abordagem do Programa de Estudo do Meio Social (6-10 anos) -do próximo para o distante; do familiar para o desconhecido; do presente para o passado; do eu para os outros- encaminham para a exploração de temáticas inseridas ou emergentes do local: "os professores deverão recriar o programa, de modo a atender aos diversificados pontos de partida e ritmos de aprendizagem dos alunos, aos seus interesses e necessidades e às caraterísticas do meio local" ${ }^{4}$. Esta abertura e flexibilidade do currículo não significa renúncia do mesmo, mas antes ter sobre este um olhar orientado para o desenvolvimento de competências nos alunos a partir de situações de aprendizagem que emergem de problemas de interesse pessoal, social e local. Assim se poderão alcançar os principais objetivos do currículo institucionalizado ${ }^{5}$, fomentando nas crianças uma mentalidade investigativa (Félix \& Roldão, 1996). Neste âmbito, o estudo e a aprendizagem da História e da Geografia com recurso ao meio local pode ser altamente motivador, cabendo à localidade o papel de "espaço laboratorial" (Alves, 2006, p. 69) onde professor e aluno trabalham em

\footnotetext{
2 Ministério da Educação (2004), Organização Curricular e Programas do Ensino Básico, $2^{\circ}$ Ciclo, vol. I, pp. 77-78.

3 Ministério da Educação (2004), Organizacãa Curricular e Programas do Ensino Básico, p. 83.

4 Ministério da Educação (2004), Organização Curricular e Programas do Ensino Básico, p. 102. Um dos objetivos gerais do programa do Estudo do Meio é o de "reconhece e valorizar o seu património histórico e cultural” (p. 104)

5 Portanto, aquilo que parece ser um paradoxo -a construção de um currículo localizado em detrimento do cumprimento do currículo generalizado- não o é na medida em que o professor parte das especificidades próximas para atingir determinados objetivos.
} 
conjunto sobre uma realidade que lhes está próxima. Neste sentido, entendemos por currículo local um conjunto de saberes que emergem de um contexto histórico-geográfico próximo e particular, não em sobreposição mas paralelamente ao currículo nacional, e que se pretende que vá "ao encontro dos interesses dos diferentes participantes do processo educativo, alunos, professores e comunidade, sem evidentemente comprometer os objetivos naturalmente fixados pela escola" ${ }^{1}$.

Neste estudo mobilizamos os conceitos de currículo local e de património, ensaiando analisar os significados que decorrem da invisibilidade dos lugares, a fim de analisar as competências histórico-geográficas que é possível desenvolver em crianças dos 6 aos 12 anos. Na definição do lugar não nos restringimos à dimensão física do mesmo, valorizamos sim uma abordagem que emerge do conceito de território, integradora de diferentes dimensões sociais (Haesbaert, 2004), isto é, o lugar como espaço natural, espaço cultural, espaço económico e espaço político.

Conhecer o património ${ }^{7}$, sobretudo o património local, significa descobrir o que o lugar oferece em termos de testemunhos patrimoniais (materiais e imateriais) que podem despertar o aluno para a preservação e defesa de um território que é seu por proximidade física ou afinidade cultural (Coma, 2009; Ferreira, Martins, Hortas, \& Dias, 2012; Hernandez, Barandica \& Quintela, 2009; Prats \& Santacana, 2009). Noutra perspetiva, o recurso ao património local pode ser uma estratégia importante, não como contraponto ao currículo nacional mas enquanto auxiliar da dimensão da memorização dentro da sala de aula (Jiménez \& Gaite, 1996) através, por exemplo, de visitas de estudo e trabalho de campo. Esta interação, por via da exploração do lugar, permite ao aluno viver no seu meio próximo um conjunto de experiências que lhe servirão para completar o seu livro de conhecimentos e adquirir uma visão da realidade mais plural e rica de acontecimentos e significados (Roldão, 2001).

Nos contextos históricos e geográficos próximos são mobilizados recursos e lugares que classificamos de visíveis e invisíveis. Porém, se definir o que entendemos por visível é uma tarefa simples, pois associamos a algo que se pode ver, que é percetível, que é evidente, que é claro ou que é aparente, definir a invisibilidade coloca-nos várias interrogações: invisível porquê? invisível por quem? e, ainda, invisível quando? Assumimos, neste estudo, que a invisibilidade dos lugares se associa a um desconhecimento generalizado dos cidadãos que por eles passam todos os dias, definindo-se como lugares invisíveis, porque mantêm ocultos os signi-

6 A citação, retirada de Alonso (1998, p. 402), é de Freitas (1995), Caminhos para a descentralização curricular. Colóquio Educacão e Sociedade, no 10, p. 114. O professor não deve ser um consumidor do currículo nacional mas antes fazer uma gestão equilibrada tendo em conta as potencialidades geográficas e até históricas do meio onde se insere a escola, bem como a caracterização do grupo de alunos.

7 A Lei do Património Cultural Português declara ser este constituído por "todos os bens materiais e imateriais que, pelo seu reconhecido valor próprio, devam ser considerados como de interesse relevante para a permanência e identidade da cultura portuguesa através do tempo" (Manique \& Proença, 1994, p. 55). ficados espácio-temporais que resultam da sua localização, da relação que estabelecem com a cidade, das suas origens mais remotas e das funções que desempenharam nas diferentes épocas que atravessaram.

\section{Didática das Ciências Sociais na Escola Superior de Educação de Lisboa: uma experiência formativa}

O quadro teórico em que situamos a unidade curricular de THGP está orientado para o aprofundamento de temas emergentes dos programas do $1^{\circ}$ e $2^{\circ}$ ciclos do Ensino Básico (6-12 anos) no âmbito das Ciências Sociais, especificamente de História e Geografia. Para esta unidade curricular são mobilizados conhecimentos históricos e geográficos desenvolvidos nos três anos anteriores da formação inicial. A construção de projetos a partir de um levantamento dos recursos patrimoniais locais (materiais e imateriais) privilegia assim um contexto de ação (Perrenoud, 1998) que conduz ao desenvolvimento de competências nos seguintes âmbitos: investigação histórica e geográfica; contextualização, análise e compreensão dos fenómenos sócio-espaciais; comunicação em História e Geografia; tomada de decisões na gestão e organização científica dos programas destas disciplinas; articulação dos conteúdos e objetivos com outras disciplinas e áreas disciplinares, numa perspetiva de trabalho interdisciplinar; e gestão flexível dos currículos e programas do Ensino Básico, numa lógica de construção de currículos locais (Ferreira, Martins, Hortas, \& Dias, 2012).

A construção dos trabalhos obedeceu a uma lógica de metodologia de trabalho de projeto, operacionalizada numa sequência de ações que permitem produzir uma representação antecipada de um processo de transformação da realidade (Guerra, 2002). Pretende-se, assim, uma construção em progressão que emerge das condições/problemáticas identificadas através de um diagnóstico ${ }^{8}$, perseguindo objetivos previamente definidos, e que ao projetar-se permitirá, ao longo da sua construção, modificações e ajustes, sem contudo abandonar o plano inicial (Silva, 2006). É, portanto, uma construção que antecipa, ou que projeta a intervenção ou a mobilização de uma realidade particular através de um planeamento ${ }^{9}$ sistemático do trabalho, integrando uma sequência

8 O diagnóstico é uma busca de respostas a um problema que, no caso dos projetos analisados, é a compilação da informação relativa ao território escolhido. Constitui-se como um processo investigativo que se socorre de técnicas de pesquisa. O resultado é a aquisição de um conhecimento científico e fundamentado sobre o meio proposto como pano de fundo para o projeto, ainda que não definitivo pois assinala as necessidades a preencher e define linhas de pesquisa e de aprofundamento (Guerra, 2002).

9 "planear é, simultaneamente, uma forma de saber o que se pretende e de mobilizar os recursos existentes e uma formação contínua" (Guerra, 2002, p. 120). O planeamento é "indispensável para que o projeto possa passar da intenção à ação, incide na definição concreta das metas a atingir e das ações a realizar" (Silva, 2006, p. 3). 
ordenada de etapas tendo em conta a concretização dos objetivos previamente definidos. No contexto específico da unidade de THGP, os projetos desenvolvidos obedecem à seguinte estrutura:

a) identificação de um território e sua caraterização, através de um trabalho de pesquisa bibliográfica e de trabalho de campo, que conduzem à produção de um diagnóstico do património natural, social e cultural, teoricamente fundamentado com recurso a conhecimentos da História e da Geografia;

b) construção do projeto: (1) definição dos objetivos gerais ${ }^{10}$, fundamentando-os teoricamente com base nos documentos orientadores do Ensino Básico; (2) definição das estratégias gerais em articulação com os objetivos; (3) definição dos objetivos específicos, atividades, recursos, indicadores e instrumentos de avaliação ${ }^{11}$. Foi ainda pensada a integração curricular a partir das atividades definidas e esquematizada a sua operacionalização.

Os projetos que suportam a análise que aqui apresentamos foram desenvolvidos na cidade de Lisboa, recorrendo a um leque diverso de lugares e elementos simbólicos do património material e imaterial, para serem explorados com alunos de idades entre 8 e 12 anos. São exemplo dos lugares da cidade onde se localizam os recursos patrimoniais: a freguesia da Ajuda, Belém, a Baixa Pombalina, o Largo de S. Domingos, o Chiado, o Bairro Alto, a Graça e S. Bento. Sobre os recursos patrimoniais visíveis que foram mobilizados são referência o Palácio da Ajuda, a Torre de Belém, o Mosteiro dos Jerónimos, a Igreja de S. Domingos, o monumento de homenagem ao povo judeu, o mural de Lisboa Cidade da Tolerância, o Elétrico 28, as Vilas Operárias da Graça, o Palácio de S. Bento, os ascensores de Lisboa, o Museu de História Natural e as obras arquitetónicas do Estado Novo. A estes elementos do património edificado juntam-se ainda a toponímia de algumas ruas da cidade, os recursos naturais, culturais e sociais da área central da cidade e o fado enquanto canção associada a alguns bairros históricos de Lisboa.

Retomando a ideia de lugares invisíveis, associado ao ocultar dos significados espácio-temporais que resultam da sua localização, da relação que estabelecem com a cidade, das suas origens e das funções que desempenharam em diferentes momentos da história, procuramos, a partir dos lugares e dos recursos visíveis, ir ao encontro das dimensões que

10 Os objetivos gerais "descrevem grandes orientações para as acções e são coerentes com as finalidades do projecto, descrevendo as grandes linhas de trabalho a seguir... são globalizantes e geralmente não são datados nem localizados com precisão, sendo, no entanto, formulados em termos de verbos de acção" (Guerra, 2002, pp. 163-164).

11 Ainda que a proposta seja feita para um ciclo de ensino diferente, sobre as diferentes fases da metodologia de trabalho de projeto ver o trabalho de Teresa Vasconcelos (1998), Das perplexidades em torno de um hamster ao processo de pesquisa: Pedagogia de projecto em educação pré-escolar em Portugal. In Departamento de Educação Básica (Org.). Qualidade e Projecto na Educacãa Pré-Escolar, pp. 123-158. Lisboa: DEB.
Ihes conferem invisibilidade. No projeto desenvolvido na freguesia da Ajuda, associamos à dimensão espacial da invisibilidade a importância da localização daquele lugar na cidade de Lisboa à época do terramoto de 1755, por não ter sido afetado pelo mesmo, e por nele se ter instalado a "Real Barraca"12, conferindo a uma área remota da cidade uma nova posição/relação no contexto urbano pós terramoto, sustentada nas funções inerentes à centralidade política que lhe foi atribuída. As mesmas dimensões da invisibilidade -localização, relação e função- são identificadas em Belém, a partir da Torre e do Mosteiro dos Jerónimos, recursos localizados na margem direita do estuário do Tejo, importante ponto de partida e de relação com o império, símbolos da singularidade do estilo manuelino associado a uma época de descobertas e de afirmação de Portugal no mundo.

Outros significados ocultos surgem associados às funções desempenhadas pelos lugares em épocas distantes e que só é possível descobrir pela pesquisa e procura de significado para os elementos simbólicos que neles hoje se encontram. Situamos nesta dimensão temporal da invisibilidade o Largo de S. Domingos pela carga simbólica dos monumentos que hoje o caraterizam e que pretendem conferir a este lugar uma imagem de acolhimento e aceitação da diversidade religiosa e cultural que habita a cidade de Lisboa, contrariando/escondendo a função que outrora desempenhou como espaço de manifestação da intolerância religiosa vivida na cidade e materializada pela perseguição do povo judeu ${ }^{13}$.

No percurso do Elétrico 28 registamos diversos elementos que nos transportam para a descoberta da história e das sociabilidades outrora vividas na área central da cidade por classes sociais diversas, e que se encontram representadas através da estatuária e da toponímia do local. A posição destes espaços na cidade e as funções que em diferentes épocas desempenharam só se tornam visíveis pela pesquisa sobre os nomes e histórias de vida que a eles estão associados e que conferem aos lugares significados até então invisíveis.

A exploração da localização e relação dos ascensores de Lisboa com os espaços envolventes que servem desvela a importância da evolução da tecnologia, desencadeada pela revolução dos transportes, na melhoria das acessibilidades e da mobilidade entre espaços e na reconfiguração de novos usos e funcionalidades. Também como símbolo de uma época, as obras arquitetónicas do Estado Novo ${ }^{14}$ tornam visível uma ideologia, uma época e uma forma de fazer-cidade que se distingue dos momen-

12 Nome dado pelo povo à grande casa de madeira mandada construir pelo rei D. José I após o terramoto de 1755 . O rei, com medo de futuros abalos de terra, não voltaria a dormir sob um teto de pedra até ao ano da sua morte. No reinado de D. Maria I, a Real Barraca foi demolida e no seu lugar iria nascer o Palácio da Ajuda.

13 No Largo de S. Domingos relembra-se numa lápide quase invisível o massacre de cerca de 4000 cristãos-novos ocorrido no dia 19 de abril de 1506. Sobre esse episódio leia-se de S. Mateus \& P. Pinto (2007), Lisboa, 19 de abril de 1506. O massacre dos judeus. Lisboa: Aletheia.

14 Regime político que vigorou em Portugal entre 1926 e 1974, naquela que foi a mais longa ditadura da Europa. 
tos que o antecederam e precederam. Construídas em novas áreas da cidade, abrindo novas avenidas e bairros, estas obras, imagem de marca de um regime, criaram novas dinâmicas de relação entre espaços, com impacto na forma de viver a cidade e com a atribuição de novas funções aos lugares.

Associamos ainda a este percurso de descoberta das dimensões espácio-temporais da invisibilidade dos lugares a exploração da toponímia e a sua relação com as funções dos espaços, com a história dos lugares, com as personagens e factos que marcaram épocas. Como exemplo, pode ser citado um projeto desenvolvido na área da Baixa-Chiado e que permitiu desocultar a relação entre os nomes das ruas e os autores das expedições africanas, realizadas a partir de Lisboa em direção ao mundo colonial, tornando visíveis as relações espaciais entre os dois territórios e os contributos de cada um dos heróis na história nacional.

Os exemplos que acabamos de apresentar, a partir dos projetos construídos pelos estudantes na cidade de Lisboa, conduziram à investigação sobre lugares invisíveis, revelando o modo como estes se podem constituir como valiosos recursos pedagógicos, pelos conteúdos dos programas de $1^{\circ}$ e $2^{\circ}$ ciclo do Ensino Básico que permitem explorar, pelos objetivos que é possível alcançar e pelas competências históricas e geográficas que desenvolvem nos alunos.

Assim, os projetos são concebidos de forma a garantir uma exigente coerência entre os lugares identificados, os elementos patrimoniais mobilizados, os objetivos gerais definidos e as competências histórico-geográficas que é previsível desenvolver. Em particular, no que diz respeito aos objetivos gerais, estes são definidos partindo de duas lógicas distintas, mas complementares na conceção da metodologia de projeto: as características do grupo-turma e as aprendizagens previstas nos programas e metas de aprendizagem oficialmente estabelecidas. A título de exemplo, estão no primeiro caso objetivos como "Experimentar atitudes de entreajuda entre pares e entre grupos" ou "Melhorar as competências ao nível da expressão escrita"; no segundo caso são definidos objetivos gerais como "Relacionar a toponímia de um local com factos históricos", "Caracterizar a evolução histórica dos transportes -o elétrico" ou, ainda, "Localizar factos e datas relacionados com o estilo manuelino e com a expansão marítima portuguesa, no friso cronológico, em mapas e no globo". No entanto, é sempre reforçada a necessidade de garantir que o processo de ensino e aprendizagem se desenvolva numa perspetiva de desenvolvimento de competências da História e da Geografia, as quais emergem, como veremos de seguida, das especificidades epistemológicas destas duas áreas científicas.

\section{Projetos locais, lugares (in)visíveis e desenvolvimento de competências}

Como vimos anteriormente, a conceção de projetos didáticos no âmbito do ensino da História e Geografia permite mobilizar como recursos educativos o património natural, social e cultural do território onde se realiza a prática docente. Muitos dos elementos patrimoniais mobilizados, para além das relações com o currículo nacional que são mais evidentes, transportam consigo significados distintos nas suas dimensões espácio-temporais.

Para além de serem enquadrados nos documentos oficiais do Ministério da Educação, nomeadamente os programas de "Estudo do Meio" (6-10 anos) e de "História e Geografia de Portugal" (11-12 anos), os projetos concebidos prevêem o desenvolvimento de competências que resultam da construção dos saberes científicos das áreas da História e da Geografia.

Não obstante os diferentes conceitos que têm sido avançados por diversos autores (Perrenoud, 2001; Sacristán, 2011), entendemos que a aprendizagem por competências centra-se no conjunto de conhecimentos, capacidades e atitudes que cada saber científico permite promover e desenvolver em cada criança e jovem. Assim, no caso concreto do conhecimento histórico e geográfico, se o processo de ensino e aprendizagem destas duas disciplinas das Ciências Sociais for orientado para o desenvolvimento das suas competências específicas, isto implica: (1) a mobilização dos saberes científicos (conteúdos e conceitos) previstos nos respetivos programas; (2) o desenvolvimento de capacidades que são inerentes às singularidades da construção do saber histórico-geográfico; e (3) a promoção de atitudes que se traduzem nos valores cívicos intrínsecos às finalidades do ensino da História e da Geografia.

Para além desta forma necessariamente simplificada de apresentar o conceito de competência (na medida em que o desenvolvimento desta temática ultrapassa o âmbito deste artigo), importa ainda sublinhar que a definição dos três núcleos essenciais das competências da História, assim como os da Geografia emergem, no nosso entender, das especificidades epistemológicas de cada uma das ciências em questão.

No caso da História, os três núcleos de competências definidos em $2001^{[15]}$-o Tratamento de Informação/Utilização de Fontes; a Compreensão Histórica, esta consubstanciada nos diferentes vetores que a incorporam -a temporalidade, a espacialidade e a contextualização; e a Comunicação em História- correspondem às diferentes fases de construção do saber histórico. Tendo por referência os três momentos da escrita da História, identificados por Mattoso (1988) -exame do pas-

15 Ministério da Educação. DEB (2001). Currículo Nacional do Ensino Básico. Competências Essenciais. Lisboa: Editorial do Ministério da Educação. Revogado em 2011 
sado através das suas marcas, representação mental; e produção de um texto escrito ou oral- podemos constatar que cada um destes momentos corresponde a um dos núcleos de competências atrás enunciados.

Esta clara sintonia não é, obviamente, fruto do acaso mas resulta do facto das competências essenciais definidas para uma determinada disciplina emergirem da especificidade da ciência que Ihe oferece o objeto e o método, e que fundamenta, quer o seu lugar no currículo, quer as respetivas capacidades e atitudes que poderá desenvolver junto dos jovens (Dias, 2006, p. 11).

Do mesmo modo, no que se refere à Geografia, também os seus três núcleos de competências definidas no Currículo Nacional do Ensino Básico emergem dos objetos centrais do saber geográfico-Localização; Conhecimento dos lugares e das regiões; Dinamismo da relação entre espaços- os quais explicitam o modo como o ensino da Geografia emerge da epistemologia deste domínio científico. Em última análise, a investigação geográfica e o ensino da Geografia partilham do mesmo objetivo: tornar o mundo contemporâneo inteligível interrogando a natureza das relações das sociedades com o seu espaço e o seu ambiente (Beucher \& Reghezza, 2005). E é pelo desenvolvimento daqueles três núcleos de competências que é possível às pessoas aprenderem "a ler e interpretar o mundo, a terem confiança em si no meio em que vivem, a compreenderem e respeitarem o espaço dos outros, enfim, a construírem o seu lugar no mundo e agirem nele de uma forma responsável" (Cachinho, 2000, p. 87).

Os projetos anteriormente descritos, concebidos a partir de territórios definidos na cidade de Lisboa, mobilizaram lugares que, pelo desconhecimento generalizado dos cidadãos que por eles passam todos os dias, submersos na azáfama do quotidiano de uma cidade europeia, são aqui considerados como lugares invisíveis: mantêm ocultos os significados espácio-temporais que resultam (1) da sua localização, (2) da relação que estabelecem com a cidade, (3) das suas origens mais remotas e (4) das funções que desempenharam nas diferentes épocas que atravessaram. Lugares invisíveis que se constituíram como recursos pedagógicos que, pelos conhecimentos mobilizados e pelas capacidades e atitudes promovidas, favoreceram o desenvolvimento de competências essenciais da História e da Geografia, em alunos dos 6 aos 12 anos.

De um modo geral, todos os projetos tiveram uma forte componente investigativa, pelo que promoveram competências centradas na identificação de problemas e na formulação de hipóteses, ponto de partida de um processo investigativo no campo das Ciências Sociais que, neste caso em concreto, possibilita o desenvolvimento de competências comuns à História e à Geografia. A interrogação dos lugares surge da atividade de observar e descrever os aspetos da realidade física e social durante as visitas de estudo e os itinerários pedagógicos (técnicas de trabalho de campo) previstos em cada um dos projetos, permitindo recolher informação sobre o território, quer as suas características físicas, quer económicas e sociais.
Ainda no âmbito das atividades investigativas propostas, os alunos são convidados a mobilizar diferentes fontes de informação, com diferentes linguagens, nomeadamente, fontes orais, escritas, iconográficas, cartográficas, gráficas e monumentais, e a recolher, registar e tratar diferentes tipos de informação: documental, iconográfica e gráfica.

Ao nível da comunicação, regra geral, os projetos prevêem a construção de produtos por parte dos alunos, quer como forma de sistematização da informação quer com o objetivo de divulgar à escola e à comunidade os resultados alcançados: cartazes, livros, álbuns e itinerários pedagógicos, ou dramatizações, tendo em vista recriar situações da história nacional ou local. Deste modo, os alunos são solicitados para apresentar a informação recolhida de forma clara e a utilizar diferentes formas de comunicação escrita e oral (textos, desenhos, colagens, maquetes e mapas). Quando os projetos privilegiam a vertente temporal surgem os produtos construídos pelos alunos que integram na comunicação diferentes materiais iconográficos, quer sejam gravuras e fotografias, quer sejam plantas e mapas, frisos cronológicos e árvores genealógicas, simples ou complexas, conforme as idades das crianças.

Quanto aos conteúdos dos programas de "Estudo do Meio" (6-10 anos) e de "História e Geografia de Portugal" (11-12 anos) que são mobilizados para o processo ensino e aprendizagem em torno dos lugares da cidade de Lisboa, assume particular relevo um conjunto de competências específicas da História e Geografia. No que diz respeito ao saber histórico, promove-se a utilização de vestígios de outras épocas como fontes de informação, facilitando a distinção de características concretas da sociedade em diferentes períodos. 0 desenvolvimento destas competências específicas da História permite, não só identificar, localizar no tempo e caracterizar mudanças registadas na sociedade, mas também reconhecer as formas de organização do espaço nacional em diferentes períodos. Por sua vez, os conteúdos que mais se relacionam com a vertente geográfica incidem no desenvolvimento de competências relacionadas com a leitura de mapas (escala e legenda) e a localização de lugares na cidade, de Lisboa, de Portugal, da Península Ibérica, da Europa e do Mundo. Quando os conteúdos convidam à abordagem que permite compreender o dinamismo da relação entre espaços, fica facilitado o reconhecimento dos aspetos naturais e humanos do meio, e, ainda, o modo como os diferentes espaços se integram em contextos sucessivamente mas vastos: aldeia/ bairro/vila/cidade/região/país.

Acrescente-se ainda que, quer ao nível das atividades investigativas experienciadas quer no que concerne à comunicação e aos conteúdos de História e Geografia de Portugal trabalhados com os alunos, uma última competência adquire relevância na promoção do saber histórico-geográfico, a qual remete para a capacidade de utilizar o vocabulário específico destas disciplinas científicas integradas no campo das Ciências Sociais. 
Compreendendo apenas aquelas três dimensões de análise das competências essenciais da História e da Geografia, desenvolvidas nos projetos didáticos desenhados a partir dos lugares de Lisboa-investigação, comunicação e conteúdos-, foi possível identificar um abrangente número de competências específicas transversais àquelas duas áreas do saber, contribuindo para a formação de alunos histórica e geograficamente competentes.

\section{Conclusões}

O património natural, social e cultural dos lugares da cidade pode constituir-se num conjunto de recursos fundamentais para o desenvolvimento de projetos didáticos no âmbito das Ciências Sociais e, mais concretamente, ao nível das aprendizagens da História e Geografia. No entanto, para que tal aconteça, o professor deve assumir a sua capacidade de decisão sobre a gestão do currículo e reconhecer os significados espácio-temporais mais profundos dos lugares que, de outro modo, permanecerão invisíveis aos olhos das crianças, dos jovens e, no futuro, dos cidadãos que vivem na cidade.

A experiência formativa implementada na ESELx revela a importância destes projetos, permitindo abordar componentes fundamentais da formação inicial de professores neste domínio científico e didático: a problemática da flexibilização do currículo e da relação entre currículo local e currículo nacional; a conceptualização dos conteúdos programáticos, gerindo a sua interligação com os recursos disponibilizados pelo meio envolvente; a metodologia de projeto, enquanto estratégia pedagógica central para trabalhar os lugares e o seu património.

Os projetos concebidos no âmbito da unidade curricular THGP ilustram as potencialidades que os lugares da cidade transportam quando são assumidos como recurso dentro da sala de aula, pela descoberta dos elementos visíveis, mas também das suas invisibilidades, possibilitando o desenvolvimento das competências essências da História e da Geografia e, assim, assegurando também a formação de cidadãos cientificamente competentes.

\section{Referências bibliográficas}

Alonso, M. (1998). Inovação Curricular, Formação de Professores e Melhoria da Escola. Uma Abordagem Reflexiva e Reconstrutiva sobre a Prática da Inovação/Formação. (Tese de Doutoramento) (vol. 1). Braga: Instituto de Estudos da Criança; Universidade do Minho.

Alves, L. (2006). A História local como estratégia para o ensino daHistória. Em AAvv, Estudos em Homenagem ao Professor Doutor José Marques (pp. 65-72).Porto: Faculdade de Letras da Universidade do Porto.

Beucher, S. \& Reghezza, M. (2005). La Géographie: pourquoi? comment? Paris: Hatier.

Cachinho, H. (2000). Geografia escolar: orientação teórica e praxis didáctica. Inforgeo, 15, 69-90.

Coma, L. (2009). La evaluación de las actividades patrimoniales. La ciudad y el patrimonio histórico como recursos educativos. Didáctica de Las Ciencias Sociales, 59, 22-37.

Dias, A. (2006). História de Portugal e formação inicial de professores do $1^{\circ}$ Ciclo do Ensino Básico. O "caso" Macau. (Provas Públicas). Lisboa: Escola Superior de Educação de Lisboa.

Félix, N. \& Roldão, M. C. (1996). Dimensões formativas de disciplinas do rnsino básico: História. Lisboa: Instituto de Inovação Educacional.

Ferreira, N.; Martins, C.; Hortas, M. J. \& Dias, A. (2012). Do património local ao currículo nacional: análise de projetos no âmbito das metodologias de ensino de História e Geografia para o $1^{\circ}$ e $2^{\circ}$ CEB. Escola e comunidade. (pp. 499-512). Lisboa: CIED, Escola Superior de Educação de Lisboa.

Guerra, I. (2002). Fundamentos e processos de uma Sociologia de aç̧ão. $O$ planeamento em Ciências Sociais. São João do Estoril: Principia.

Haesbart, R. (2004). O Mito da desterritorialização: do "fim dos territórios" à multerritorialidade. Rio de Janeiro: Bertrand Brasil.

Hernández, A.; Barandica, E. \& Quintela, J. (2009). Ciudad, educación y valores patrimoniales. Un compromiso de municipios de la RECE. La ciudad y el patrimonio histórico como recursos educativos. Didáctica de las Ciencias Sociales, 59, 38-46.

Jiménez, A. \& Gaite, M. (1996).Enseñar Geografía. Madrid: Síntesis.

Manique, A. \& Proença, M. (1994). Didáctica da História. Património e História Local. Lisboa: Texto. 
Mateus, S. \& Pinto, P. (2007). Lisboa, 19 de abril de 1506. O massacre dos judeus. Lisboa: Aletheia.

Mattoso, J. (1988). A Escrita da História. Lisboa: Estampa.

Ministério da Educação (2004). Organização Curricular e Programas do Ensino Básico. Lisboa: Departamento de Educação Básica.

Ministério de Educación. DEB (2001). Currículo Nacional do Ensino Básico. Competências Essenciais. Lisboa: Editorial do Ministério da Educação.

Perrenoud, P. (2001). Porquê construir competências a partir da escola? Porto: Asa.

Prats, J., \& Santacana, J. (2009). Ciudad, educación y valores patrimoniales. La ciudad educadora, un espacio para aprender a ser ciudadanos. La ciudad y el patrimonio histórico como recursos educativos. Didáctica de las Ciencias Sociales, 59, 8-21.

Roldão, M. (2001). Estudo do Meio no $1^{\circ}$ Ciclo. Fundamentos e Estratégias. Lisboa: Texto.

Sacristán, J. (2011). Educar por competências. O que há de novo? Porto Alegre: Artmed.

Silva, M. (2006). Projectos e aprendizagens: 0 projecto como projéctil não identificado. Em Actas do $2^{\circ}$ Encontro de Educadores de Infância e Professores do $1^{\circ}$ Ciclo (pp. 49-64). Porto: Areal. 